\title{
Intact neurological status after induced therapeutic hypothermia in cardiac arrest
}

\author{
Muhammad Mubashir Zahid, Rabia Shahzad Siddiqui, \\ Abdel H. Noureldin
}

\begin{abstract}
Introduction: Cardiac arrest patients in whom return of spontaneous circulation (ROSC) is achieved after resuscitation frequently develop irreversible neurological impairments owing to hypoxic injury and reperfusion induced cell death. Therapeutic hypothermia has become a standard strategy in specific unconscious adult patients with ROSC after out-of-hospital cardiac arrest (OHCA) as per American Heart Association (AHA) guidelines. Case Report: A 48-year-old South Asian male arrived to our emergency department with 20 minutes duration of OHCA with no basic life support (BLS) measures en route to hospital. His initial rhythm was ventricular fibrillation and he had ROSC after 13 minutes of cardiopulmonary resuscitation (CPR) and subsequently underwent therapeutic hypothermia for 24 hours and recovered completely without neurological impairment after eight days of incident. Conclusion: Therapeutic hypothermia in eligible cardiac arrest patients is an important component of the post-cardiac arrest care in the AHA chain of survival. The AHA chain of survival is a chain of five interdependent links for cardiac arrest and comprises early recognition, early CPR,
\end{abstract}

Muhammad Mubashir Zahid ${ }^{1}$, Rabia Shahzad Siddiqui', Abdel H. Noureldin ${ }^{2}$

Affiliations: ${ }^{1}$ Emergency Medicine Resident, Tawam Hospital, Al Ain, United Arab Emirates; ${ }^{2}$ Program Director Emergency Medicine, Tawam Hospital, Al Ain, United Arab Emirates.

Corresponding Author: Muhammad Mubashir Zahid, P.O. Box 15258, Tawam Hospital, Emergency Department, Khalifa Ibn Zayed Street, Al Maqam, Al Ain, Abu Dhabi, United Arab Emirates; Ph: 00971555806487; Email: drmubashirzahid@ hotmail.com

Received: 24 May 2014

Accepted: 01 July 2014

Published: 02 August 2014 early defibrillation, early advanced cardiac life support and post-cardiac arrest care. It has substantial benefits on patient outcome. The ease of administration and positive clinical outcome should encourage other medical professionals to avail this modality.

Keywords: Therapeutic hypothermia, Hypertrophic obstructive cardiomyopathy, Cardiac arrest

\section{How to cite this article}

Zahid MM, Siddiqui RS, Noureldin AH. Intact neurological status after induced therapeutic hypothermia in cardiac arrest. Case Rep Int 2014;3:10-13.

Article ID: 100005CRINTMZ2014

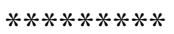

doi:10.5348/crint-2014-5-CR-3

\section{INTRODUCTION}

Out-of-hospital cardiac arrest (OHCA) is a leading cause of death worldwide. Improving Emergency medical services (EMS) services and bystander first aid measures are increasing the number of such patients presenting to the emergency departments and reaching return of spontaneous circulation (ROSC). But only $3-7 \%$ of these patients ever recovers to their baseline functionality, whereas others never come out of coma or develop persistent vegetative state [1].

Therapeutic hypothermia in unconscious survivors of OHCA has been associated with decreased mortality rate and improved neurological outcome [2]. Despite the proven benefits, many patients who are eligible for 
therapeutic hypothermia do not receive it. Reasons could be physician's lack of familiarity with the procedure, limited data, failure to incorporate into advanced cardiac life support protocol and limited availability of cooling devices [3].

Reported here is a case of OHCA due to hypertrophic cardiomyopathy, whose initial rhythm was ventricular fibrillation and who showed complete neurological recovery eight days after induction of therapeutic hypothermia following cardiopulmonary resuscitation (CPR).

The purpose of presenting this case report is to encourage and spread awareness of timely application of therapeutic hypothermia in eligible patient population.

\section{CASE REPORT}

A 48-year-old male with no past medical or family history, who worked as a helicopter mechanic was attending the graduation ceremony of his students at the airport. He was standing and enjoying his drink when he suddenly collapsed. His friends found him unconscious so they put him in a non-medical car and brought him to hospital. After 15-20 minutes of driving without any chest compressions or breathing support they arrived at the emergency department. On arrival patient was in a cardiac arrest with initial rhythm of fine ventricular fibrillation.

Ventricular fibrillation algorithm was followed with defibrillation multiple times and administration of doses of epinephrine and amiodarone. After 13 minutes of resuscitation, the patient had ROSC.

The patient was still unconscious, his pupils began to be slightly reactive to light and post resuscitation vitals were tympanic temperature of $36^{\circ} \mathrm{C}$, peripheral pulse rate $104 \mathrm{~min}$, respiratory rate $18 \mathrm{~min}$, blood pressure 99/66 $\mathrm{mmHg}, \mathrm{SpO}_{2} 98 \%$ and MAP $77 \mathrm{mmHg}$.

Among the significant initial laboratory results were lactate $12.7 \mathrm{mEq} / \mathrm{L}, \mathrm{pH}$ 7.005, $\mathrm{HCO}_{3} 15.7 \mathrm{mmol} / \mathrm{L}, \mathrm{CO}_{2}$ 64.4 mmHg, O2 $85.9 \mathrm{mmHg}$, and Trop I $0.01 \mathrm{ng} / \mathrm{mL}$

Patient's 12-lead electrocardiography was recorded at ROSC (Figure 1).

The patient was started on $2 \mathrm{~L}$ of cool saline infusion at $4^{\circ} \mathrm{C}$ by pressure bags over 30 minutes. Patient had a normal computed tomography (CT) scan of the brain and cardiac catheterization. He was shifted to the ICU, where the patient was connected to Arctic Sun $囚$, Medivance for surface cooling by appropriately sized cooling pads applied to the back, chest and thighs. The Arctic Sun $®$ temperature management system is a device intended for monitoring and controlling patient temperature. Temperature was set to $33^{\circ} \mathrm{C}$. Patient was sedated and paralyzed using fentanyl infusion and rocuronium and was mechanically ventilated. Patient's core temperature was maintained in the range of $32-34^{\circ} \mathrm{C}$ by rectal probe. After 24 hours, therapeutic hypothermia gradual rewarming was initiated at $0.5^{\circ} \mathrm{C}$ per hour until patient was warmed to $36^{\circ} \mathrm{C}$ and the cooling pads were taken off. Patient did not develop any post-therapeutic hypothermia complications.

Patient was gently weaned off sedatives by the third day and was subsequently extubated on the seventh day. On the eighth day, the patient was following commands with a GCS of 15 .

During his stay in the ICU, he had a neurology consult and no neurological pathology was found with normal electroencephalography. Lower limb deepvein thrombosis scan was also normal. Cardiology was also consulted for possible cardiac anatomic causes and echocardiography was done. Echo revealed non-dilated left ventricle with moderate-severe concentric hypertrophy consistent with non-obstructive hypertrophic cardiomyopathy (Figure 2).

Patient was started on bisoprolol 2.5 mg tablet daily and was shifted to the medical floor under care of cardiology. Patient had a planned implantable cardioverter defibrillator (ICD) inserted and was discharged on oral beta-blocker with full neurological recovery.

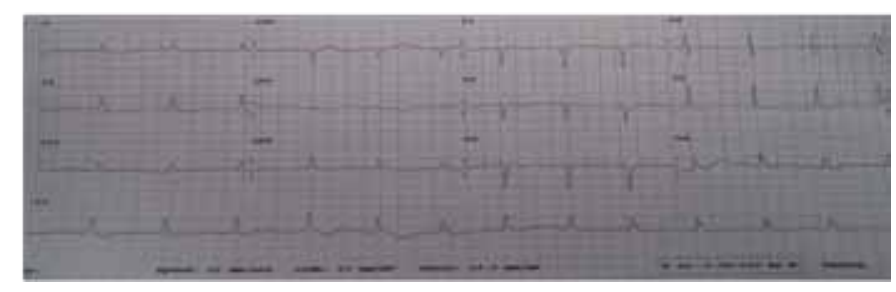

Figure 1: 12-lead ECG of patient at return of spontaneous circulation.

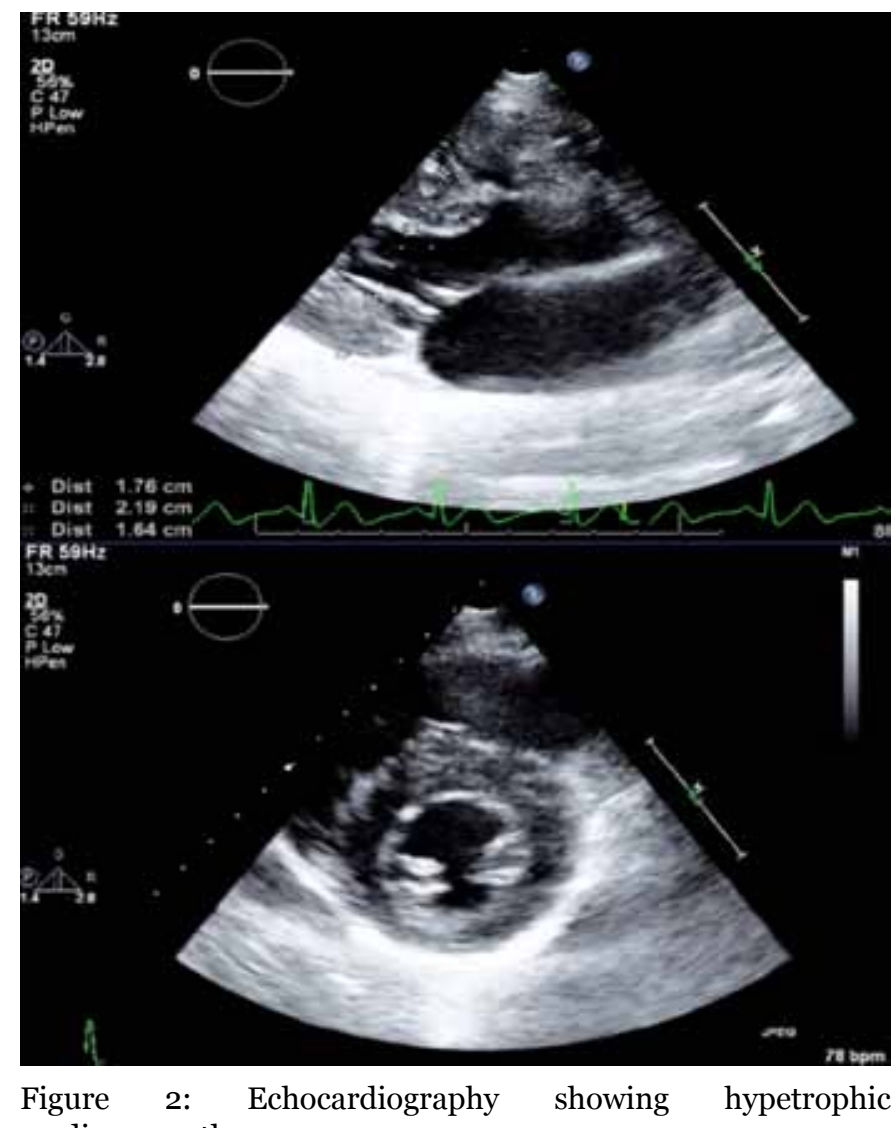

cardiomyopathy. 


\section{DISCUSSION}

Therapeutic hypothermia is one of the most significant advances in resuscitation. The case described is one of the several cases which benefited from our experience with therapeutic hypothermia. Therapeutic hypothermia is a medical treatment that lowers a patient's body temperature in order to reduce the risk of tissue injury from lack of blood flow. The lowering of body temperature may be accomplished by many means including the use cooling blankets, cooling helmets, cooling catheters, ice packs and ice water lavage. The patients who should and should not undergo therapeutic hypothermia are given in Table 1.

Hypothermia is associated with a number of adverse effects and complications. The main adverse effects reported are shivering, cardiac arrhythmia, deep vein thrombosis, pneumonia, sepsis, coagulopathy, and electrolytes and metabolic disturbances [4, 5]. However, despite the limited availability of targeted temperature management devices and adverse effects associated with the lowering of body temperature, there have been positive results on neurological outcome in many centers and case series.

Early identification of eligible patients, strict inclusion and exclusion criteria and rapid initiation of hypothermia optimizes patient outcomes. Therapeutic hypothermia should be started as early as ROSC is achieved in the emergency department with cooled saline at $4^{\circ} \mathrm{C}$ and ice bags to axilla and groin. Rapid cooling and sedation to limit cellular damage have become standard of care [6]

Table 1: Inclusion and exclusion criteria for therapeutic hypothermia.

\begin{tabular}{ll}
\hline Inclusion Criteria & Exclusion Criteria \\
$\begin{array}{ll}\text { Intubated patients with treatment } & \text { Recent major surgery } \\
\text { initiated within six hours } & \text { within 14 days - Possible } \\
\text { after cardiac arrest due to non } & \text { risk for infection and } \\
\text { perfusing ventricular tachycardia } & \text { bleeding } \\
{[\text { VT] or ventricular fibrillation }} & \\
{[\text { VF] }} & \\
\text { Patients in a coma at the time of } & \text { Systemic infection/sepsis } \\
\text { cooling } & \text { - Small increase in risk of } \\
& \text { infection } \\
\text { ROSC }<30 \text { mins from EMS/Code } & \begin{array}{l}\text { Coma from other causes } \\
\text { (drug intoxication, }\end{array} \\
\text { team arrival } & \text { preexisting coma prior to } \\
& \text { arrest) } \\
\text { Patients able to maintain a } & \text { Known bleeding diathesis } \\
\text { systolic blood pressure }>90 & \text { or with active ongoing } \\
\text { mmHg, with or without pressors } & \text { bleeding - Hypothermia } \\
\text { after CPR } & \text { may impair the clotting } \\
& \text { system (however, patients } \\
& \text { may receive chemical } \\
& \text { thrombolysis, antiplatelet } \\
& \text { agents, or anticoagulants } \\
& \text { if deemed necessary in the } \\
\text { treatment of the primary } \\
\text { cardiac condition) }\end{array}$ \\
\hline
\end{tabular}

and it reduces irreversible neurological impairments from hypoxic and reperfusion induced cell death [7-9].

\section{CONCLUSION}

This case of cardiac arrest followed by therapeutic hypothermia highlights the advantages of this treatment on patient's neurological outcome. The ease of administration and clinical outcome should encourage others to avail this modality. It can be incorporated in institutional guidelines for selected patients and must be initiated in a timely manner.

\section{$* * * * * * * * *$}

\section{Acknowledgements}

Satish Chandrasekhar Nair

(Senior Specialist, Head of Clinical Research, Academic Affairs Department, Tawam Hospital, Al Ain, Emirates of Abu Dhabi, United Arab Emirates)

- Provided technical help and writing assistance.

Arif Alper Cevik

(Assist. Professor, Internal Medicine Faculty, Specialist Physician, Emergency Medicine, United Arab Emirates University College of Medicine and Health Sciences Al Ain, United Arab Emirates)

- Provided help in case analysis.

\section{Author Contributions}

Muhammad Mubashir Zahid - Substantial contributions to conception and design of this manuscript, Acquisition of data with analysis and interpretation of data, Drafting of this manuscript and revising it for important intellectual content, Final approval of the version to be published.

Rabia Shahzad Siddiqui - Contributed to conception and design of this manuscript, Acquisition of data with analysis and interpretation of data, Drafting of this manuscript, Final approval of the version to be published. Abdel H. Noureldin - Substantial contributions to conception of this manuscript, Drafting and revising it for important intellectual content, Final approval of the version to be published.

\section{Guarantor}

The corresponding author is the guarantor of submission.

\section{Conflict of Interest}

Authors declare no conflict of interest.

\section{Copyright}

(C) 2014 Muhammad Mubashir Zahid et al. This article is distributed under the terms of Creative Commons Attribution License which permits unrestricted use, distribution and reproduction in any medium provided the original author(s) and original publisher are properly credited. Please see the copyright policy on the journal website for more information. 
6. Nolan JP, Morley PT, Vanden Hoek TL, et al.

\section{REFERENCES}

1. Geocadin RG, Koenig MA, Jia X, Stevens RD, Peberdy MA. Management of brain injury after resuscitation from cardiac arrest. Neurol Clin 2008;26(2):487506.

2. Bernard SA, Gray TW, Buist MD, et al. Treatment of comatose survivors from Out-of-hospital cardiac arrest with induced hypothermia. $\mathrm{N}$ Engl $\mathrm{J}$ Med 2002;346(8):557-63.

3. Abella BS, Rhee JW, Huang KN, Vanden Hoek TL, Becker LB. Induced hypothermia is underused after resuscitation from cardiac arrest: A current proactive survey. Resuscitation 2005;64(2):181-6.

4. Rincon F, Mayer SA. Therapeutic hypothermia for brain injury after cardiac arrest. Semin Neurol 2006;26(4):387-95.

5. Akca O. Complications of hypothermia. In: Mayer SA, Sessler DI. Therapeutic Hypothermia. New York: Marcel Dekker 2005:179-210.
Therapeutic hypothermia after cardiac arrest: An advisory statement by the advanced life support task force of the international Liaison Committee on resuscitation. Circulation 2003;108(1):118-21.

7. The hypothermia after cardiac arrest study group. Mild therapeutic hypothermia to improve neurological outcome after cardiac arrest. N Engl J Med 2002;346(8):549-6.

8. Polderman KH. Application of therapeutic hypothermia in the ICU: Opportunities and pitfalls of a promising treatment modality. Part 1: Indications and evidence. Intensive Care Med 2004;30(4):55675 .

9. Ambrosio G, Zweier JL, Flaherty JT. The relationship between oxygen radical generation and impairment of myocardial energy metabolism following post ischemic reperfusion. J Mol Cell Cardiol 1991;23(12):1359-74.
Access full text article on other devices

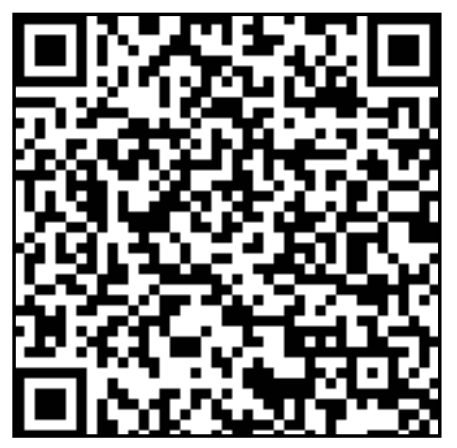

Access PDF of article on other devices

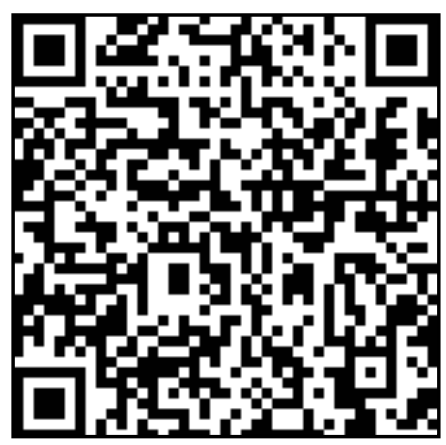

